\title{
THE TREATMENT OF THE SPEECH HANDICAPPED CHILD IN B.A.O.R.
}

\author{
Major M. R. PEACOCK M.B., F.R.C.S., D.L.O., R.A.M.C.
}

British Military Hospital, Rinteln

SUMMARY: The types of speech defect in children are briefly described. The mode of presentation and the problems of management of such children in B.A.O.R. are reviewed. It is concluded that the speech therapy services would be more effective if unified under the control of the Army Medical Services. Many children with less serious speech defects can be treated by interested and sympathetic school teachers who have had training and guidance from the area speech therapist.

\section{Types of speech defects}

Speech impairment is a disorder that can cause distress not only to the patient but also to his family. In order to present the problems arising in B.A.O.R. the types of defect will be discussed. A simple classification of speech defects is shown in Table I.

Table I

A classification of speech defects

\begin{tabular}{l|l}
\hline \multicolumn{1}{c|}{ Classification } & \multicolumn{1}{c}{ Classification } \\
\hline $\begin{array}{l}\text { The Late Talker } \\
\text { a. Due to lack of stimulation } \\
\begin{array}{l}\text { Deafness } \\
\text { Brain damage }\end{array}\end{array}$ & Dyslalia \\
b. Due to specific speech disorders & Dysphonia \\
\hline Dysfluency & $\begin{array}{l}\text { Secondary Speech Defects Due to- } \\
\text { a. Deafness. b. Brain damage. c. Mental } \\
\text { retardation. d. Psychiatric disorders. }\end{array}$ \\
\hline
\end{tabular}

The late talker

The child who has no recognisable words by the second birthday is considered to be late in talking.

The major cause in B.A.O.R. is a lack of stimulation which occurs under a number of circumstances. For example the only child, particularly if conceived late in life, may have its every need satisfied by its doting parents before it can recognise that need itself. To such a child words are superfluous. In a similar way the child at the end of a large family does not require complex speech in order to communicate.

More serious is the lack of stimulation resulting from the parent not speaking to the child. This often occurs with parents who do not fully understand speech development and "feel silly" talking to a baby that neither understands nor replies.

In B.A.O.R. there are a large number of bilingual families. Although many children have little difficulty in learning two languages at the same time, some react by failing to 
learn either. The problem may be aggravated by conflict between the parents as to which is to be the dominant language of the household.

Despite adequate stimulation late talking can be due to many causes. If such a cause can be identified e.g. brain damage, deafness etc., it is called a secondary speech defect. If there is no obvious cause then it is called a specific speech disorder.

There are a small number of children who make no attempt to speak until well after their second birthday and then progress normally. There is frequently a family history of late talking.

\section{Dysfluency}

Dysfluency is a term used to describe a disorder of rhythm better known as the "stammer" or "stutter". The cause is not known but it is said to be common in left handed children forced to use their right hands. Crossed laterality, that is a right handed, left footed or left eyed person, is not an uncommon finding. The condition also occurs when the parents are impatient or continually interrupt or prompt the child.

\section{Dyslalia}

The term dyslalia is used as the generic name for the specific speech disorders. In these patients the pattern of speech production is abnormal. The defect can be a peripheral disorder of speech muscle control or a central disorder of understanding. Frequently both systems are involved. As previously mentioned the aetiology is unknown.

The speech is bizarre in its structure, tone, rhythm, nasality and articulation. Usually it is one facet that predominates, but all may be affected so that the sufferer is rendered unintelligible to all but his familiars.

It is common to find other evidence of poor muscle control in these patients such as squints, clumsiness, expressionless faces and crossed laterality.

\section{Dysphonia}

Dysphonia is a disorder of voicing or laryngeal voice production. In childhood the majority of the problems are the concern of the otolaryngologist, therefore they will not be discussed further.

\section{Secondary speech defects}

This is a group of disorders with known aetiology. For example a congenital deafness can cause a child to be late in talking, whereas an acquired deafness will cause a cessation of speech development. Brain damage can affect both, the language giving a dysphasia, and the muscles giving a dyslalia.

In a similar way mental retardation and psychiatric illness such as autism or severe emotional disturbance can affect speech and language.

\section{Referral of patients to speech therapy}

It would seem that most patients should be seen at the request of the parents. However they learn to understand the most deviant of speech patterns in their own child so that a surprising number of patients are referred by other people. 
The child's close contacts

The primary school teacher is so busy that he has no time to spend in trying to understand peculiar speech. They tend to refer children within a week or two of them starting school. Normally they will send a note to the parent or school doctor.

The family doctor may be the first to recognise a speech defect in a child. He may do this whilst seeing another member of the family or at his routine screening clinic. About two thirds of patients are referred in this way to this clinic.

\section{The hospital specialist}

The remaining one third of the patients are referred to the speech therapist by the hospital specialists. The otolaryngologist, paediatrician and the psychiatrist see most of these patients, but referrals are seen from other departments from time to time.

\section{The nature of speech therapy}

Some idea of the methods used can be gained by studying the speech therapy department of a military hospital serving a population of some 50,000 people. A large number of these patients are young children.

Each patient is assessed, diagnosed and therapy is planned. A defect with a simple aetiology may take only 30 to 60 minutes to assess but a more complex one may take many hours of joint consultation between therapist, otologist, paediatrician, psychiatrist, psychologist and social worker.

After this assessment the child is allocated speech therapy time. This is normally in half hour sessions, being the longest time that most small children can concentrate. These sessions are held once each week, fortnight or month depending on the child's needs and capabilities.

Even though the therapist may choose a weekly schedule this is not sufficient to treat most speech defects. To be effective the therapy must continue all day, every day. To this end the therapist spends time instructing the parents so that they might continue the treatment at home. In B.A.O.R. there are a large number of immature young parents with little home support so that continuing therapy of this type is not always available. All findings and notes on progress must be committed to paper for continuity and information.

This department sees 12 new patients each month. There are 120 children undergoing therapy and a further 12 on the waiting list. To ease the strain on the waiting lists an additional 85 children are seen on weekly school visits.

This is a heavy work load and short cuts have to be taken so that as many patients as possible can be seen. Children with similar defects are seen in groups of up to six at a time. Children with minor defects cannot be offered treatment.

\section{Discussion}

The charter of the British Forces Education Service (B.F.E.S.) includes no provision for the handicapped child. This means that such children must be educated in the United Kingdom either as boarding pupils, or with their parents on a compassionate posting 
for the duration of their schooling. For a relatively small organisation spread over a relatively large area, as are the armed forces, it is the only solution to a difficult problem.

There is one major flaw in this policy of non-involvement, namely the speech impaired child. The reasons for this are that many of the speech problems can present in the pre-school child whose educational placement is not the concern of B.F.E.S. Secondly, in the school child many of the defects are of a degree insufficient to warrant special schooling. For this latter group of children in B.A.O.R. the B.F.E.S. employ 3 speech therapists. Each of these therapists works in a medical unit and therefore has many pre-school children referred to her.

In addition to the B.F.E.S. therapists each hospital in B.A.O.R. is allowed 20 hours of speech therapy time to cover pre-school, school and adult patients. These posts are for locally employed civilians so that there is often difficulty in finding suitable applicants. At the present time only 2 of the four posts are filled.

In the past the employment of therapists by two different authorities has given rise to much ill will in the division of responsibility. Indeed problems of this nature still arise.

It is worth considering what are the effects of a speech impediment on a child. Broadly speaking the implications are felt in the fields of education and social life.

The child starting school with a speech defect is at a disadvantage which increases with age. If the child cannot speak clearly it is not able to ask the teacher to clarify points of difficulty. Similarly the teacher is loath to ask the child questions for fear of delaying or confusing the rest of the class. The teacher child relationship fails on both sides, but only the child suffers. The more complex the work the worse the situation becomes.

In social life the child may only be able to communicate easily with its own parents. This will stunt the childs emotional growth. Frequently other children tease the speech impaired child so that he tends to withdraw from society as well as school life.

In B.A.O.R. there is also the problem of geography in that it is possible for a patient to travel for four hours for a thirty minute appointment thus missing most of a days schooling.

In order to rationalise the speech therapy services it is felt that the employment of all therapists by a single authority would enable a proper command and control structure to be established. As patients of all ages are seen it would seem logical to choose the Army Medical Service rather than B.F.E.S. as that employer.

Recently it has been suggested that a civilian advisor in speech therapy should be appointed to the Ministry of Defence. Her task would be easier with a single command structure.

The boundaries should be the same as those of the hospital clinical area rather than on school population. To provide a proper service to the schools each hospital should employ two full time therapists. One of the senior therapists could then be nominated as chief therapist for B.A.O.R. The new structure allows for the standardisation of departmental equipment and funds.

In this area a second line of approach has been used to ease the burden on the therapist. School teachers have been invited to attend short courses on the management 
of the minor speech defects. These courses last for two or three hours. When a suitable patient is found the therapist contacts one of the trained teachers and gives him a course of treatment for the child to follow. It is then only necessary for the therapist to see the child occasionally to assess progress and modify the treatment accordingly. So far this scheme has given very satisfactory results. Indeed the main problem is in restraining the enthusiastic teacher.

\section{Acknowledgements}

My thanks are due to Mrs. Rosemary Precious, Colonel Cameron Moffat and Major Peter Jebson for their help and encouragement in the preparation of this paper. 